\title{
Mathematical modelling: case of Haoud Berkaoui
}

Abderrahmane MELLAK - Hydrocarbons and Chemicals Faculty - Director of Laboratory of Hydrocarbon Engineering (LGPH), Université M'Hamed Bougara de Boumerdès, Algérie.

Érkezett: 2018. 08. 18. - Received: 18. 08. 2018. - https://doi.org/10.14382/epitoanyag-jsbcm.2019.3

\section{Abstract}

Research has been done in the Physics Laboratory in the School and Observatory Physics of Strasbourg consist of placing in a theoretical frame necessary to a better comprehension of the severe problem of the collapsing of the Haoud Berkaoui well (creation of a huge underground cave and important collapsing of the surface ground due to a bad drilling of a petroleum well in the south of Algeria) and especially mathematical modelling.

Keywords: geomechanics, Haoud Berkaoui, environment, major collapsing, rupture criterion, modelling.

Kulcsszavak: geomechanika, Haoud Berkaoui, környezet, kiterjedt tönkremenetel, törési feltétel, modellezés.

\section{Introduction}

The problem of Haoud Berkaoui is a difficult problem to solve, it is a rare case and perhaps unique in the world. The research work developed mainly at the School and Observatory of Physics of the Globe of Strasbourg (Mellak, A., Reuschlé, T. and Gueguen Y, 1990) essentially consists in the modelling of the delicate problem of collapse of the oil well of Haoud Berkaoui. An oil well was drilled, which never reached its objective because of many technical problems including the uncontrolled eruption of the Albian; very large freshwater aquifer zone (this water table is about $500 \mathrm{~m}$ thick and extends over several hundred kilometers) and very eruptive (it is located at about $1000 \mathrm{~m}$ deep and has a pressure of $13.8 \mathrm{MPa}$ ), that created a large hole underground by leaching out of the salt formation.

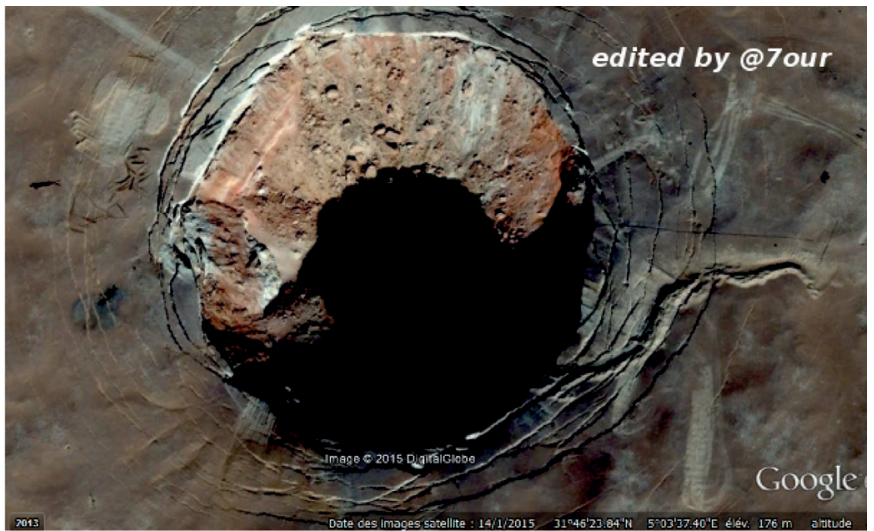

Fig. 1. Satellite photo of 14 January 2015 showing Haoud Berkaoui crater with a diameter of approximately 350 m (Credits: Google Earth)

1. ábra A Haoud Berkaoui kráter müholdképe 2015. január 14-én; a kráter átmérője kb. $350 \mathrm{~m}$

In fact, the Albian's freshwater is pressurized back to the salt (this layer is about $200 \mathrm{~m}$ thick), the sodium chloride dissolves, and the salty water has taken the place of the salt. This dissolution of the sodium chloride enlarged the subterranean hole, and after a while, large surface cracks formed, followed by a major collapse creating an imposing crater of about $350 \mathrm{~m}$

Prof. Abderrahmane MELLAK

Director of the Laboratory of Engineering Physics of Hydrocarbons and Professor and Researcher Lecturer at the Faculty of Hydrocarbons and Chemistry of the University of Boumerdes, Algeria. He is an engineer in Oil Drilling (graduated in Algeria) and also holds a DEA (Diploma of Advanced Studies), a DESS (Diploma of Specialized Higher Studies) and a PhD, obtained in French Universities. Responsible for a team of researchers, Head of Bachelor and Master Drilling Wells, frames of United Engineers, Master, the Magister and Doctorates. Member of the National Commission of University Habilitation Programs (CNH) and the National Commission for the Evaluation of Algerian Universities (CNE), the Ministry of Higher Education and Scientific Research. Participated in world congresses and nationa and international conferences with papers and has several publications in recognized nationa and international journals. Participated in severa television round tables (Canal Algeria, UFC) on the Quality of Higher Education, the UniversityBusiness Relationship). Attended the 26th World Gas Congress (WGC), held in Paris from June 1st to 5 th, 2015 .

in diameter and about a hundred meters deep (Fig. 1). While currently the surface dimensions of the big hole of Berkaoui are known, the boundaries of the underground hole are imprecise.

The present research work consists of:

1. Modelling of the underground hole into an elliptically shaped hole (this is the geometric form that can be closer to the real case and can be treated by simple methods);

2. Determination of the complex potentials according to the geometries encountered (case of the ellipse);

3. Calculation of stress and displacement fields at the surface;

4. Programming (in Fortran) of the problem considering two cases:

a) Cases where the pressure is considered uniform in the underground cavity,

b) Cases where the pressure is not uniform in the underground cavity.

5. Plots and interpretation of the curves of stresses and displacements;

6. Determination of a criterion of rupture.

\section{Modelling}

The problem of Haoud Berkaoui (HBK) can be treated as a first approximation as a plane elasticity problem in an infinite medium. We consider a system consisting of an infinite thin plate pierced with a hole (the underground cavity) approximated in this case by an ellipse. The center of this ellipse is located at a distance $\mathrm{H}$ from a line representing the plot of the Earth's surface ( $\mathrm{H}$ represents the depth of the center of the ellipse). The long axis of the ellipse is parallel with the straight line (the cavity is horizontal) and it is considered that the fluid pressure inside the cavity is negligible compared to the weight of the overlying terrain. 
In fact, we try in our case to do a modeling of the elastic deformation in the plate especially at the level of the line on the surface. Surface deformations are significant in the case of HBK (collapses, wide and deep fissures). Also, in order to examine the mechanical relation between the hole loading and the rupture process, we neglect at first the geometrical irregularities (the surface of the Earth is not uniformly flat) and the non-homogeneity of the terrains by compared to the elastic modulus.

In order to make the problem mathematically treatable we assume that the plate is homogeneous and isotropic. Let $a$ and $b$ be the half-big and small axes of the ellipse respectively. The major axis of the ellipse is carried by the abscissa axis (Ox). It is a question of calculating the complex potentials ${ }^{*}(z)$, where $\mathrm{z}=\mathrm{x}+\mathrm{iy}$, knowing the conditions of constraints to the limits imposed on the system.

\section{Transformation of the plane}

To solve the problem, we proceed to a change of variable which makes the point $\mathrm{M}(\mathrm{z})$ of the plane $(\mathrm{O}, \mathrm{x}, \mathrm{y})$ the image by the conformal transformation $\omega$ of a point $\mathrm{P}(\zeta)$ of the plane $\left(\mathrm{O}, \zeta_{1}, \zeta_{2}\right)$ with :

$\mathrm{z}=\omega(\zeta)=\mathrm{R}\left(\zeta+\mathrm{m} \zeta^{-1}\right) \quad \mathrm{R}>0, \mathrm{~m} \geq 0$
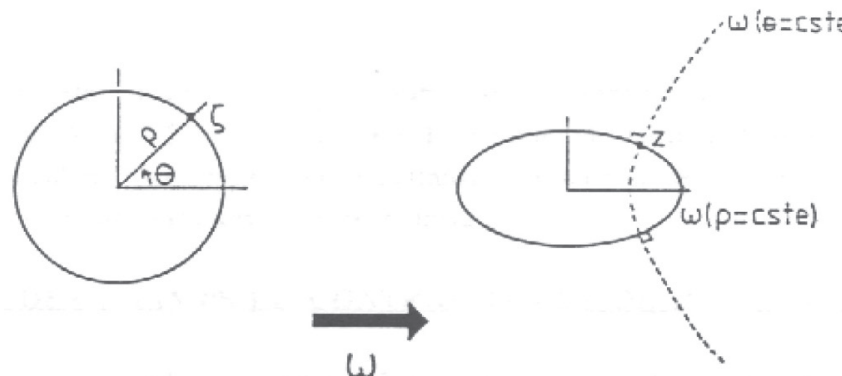

Fig. 2. Transformation of the plane

2. ábra Síktranszformáció

A circle of radius $\rho$ is transformed into an ellipse $\omega(\rho=$ constant), and the direction line $\theta$ into a branch of hyperbola $\omega(\theta=$ constant $)$. The two curves are orthogonal in $z=\omega(\zeta)$.

We see $\zeta=\rho \mathrm{e}^{\mathrm{i} \theta}$, that this transformation corresponds to a circle $(\rho=$ constant $)$ of the plane $\left(\mathrm{O}, \zeta_{1}, \zeta_{2}\right)$ an ellipse in the plane $(\mathrm{O}, \mathrm{x}, \mathrm{y})$ (Fig. 2.). The half-axes of the ellipse are given by:

$$
\mathrm{a}=R\left(\rho+m \cdot \rho^{-1}\right) \quad b=R\left(\rho-m \cdot \rho^{-1}\right)
$$

By putting $\mathrm{R}=(\mathrm{a}+\mathrm{b}) / 2$ and $\mathrm{m}=(\mathrm{a}-\mathrm{b}) /(\mathrm{a}+\mathrm{b})$, we find that the elliptic hole is the image of the circle of radius $\rho=1$ in the plane $\left(O, \zeta_{1}, \zeta_{2}\right)$, that is to say that at every point of the ellipse is associated a point $\zeta$ such that $|\zeta|=1$. Fig. 3 illustrates the relation between $\theta$ and the position of $\mathrm{M}(\mathrm{z})$ on the ellipse.

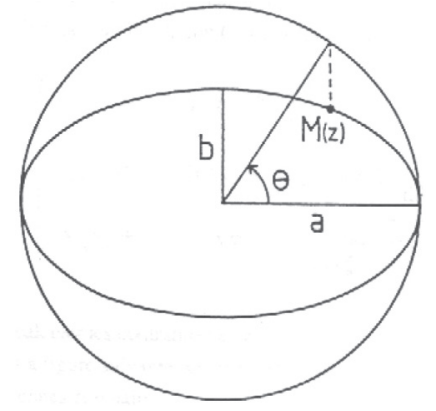

Fig. 3. Relationship between $\theta$ and the position of $M(z)$ on the ellipse

3. ábra Kapcsolat a $\theta$ szög és az M(z) függvény között az ellipszisen

The domain outside the ellipse, ie the solid, corresponds in the plane $\left(\mathrm{O}, \zeta_{1}, \zeta_{2}\right)$ to the domain in which $|\zeta| \geq 1$. When $\mathrm{m}=$ 1 , we obtain the case of the crack and for $m=0$ the case of the circular hole. So from this transformation of a circle, we will be able to solve the different cases in our work.

\section{Calculation of the fields of constraints and displacement}

The resolution of a plane elasticity problem will consist of calculating the complex potentials $\varphi(z)$ and $\psi(z)$, and then calculating the stress and displacement fields at any point $\mathrm{M}(\mathrm{x}$, y) of the solid using the relations of Kolosov-Muskhelishvili (Muskhelishvili, 1977) which define the plane state from potentials $\varphi$ and $\psi$.

$$
\left\{\begin{array}{l}
\sigma_{x x}+\sigma_{y y}=4 \Re \mathrm{e}\left[\varphi^{\prime}(z)\right] \\
\sigma_{y y}-\sigma_{x x}+2 \mathrm{i} \sigma_{x y}=2\left[\bar{z} \varphi^{\prime \prime}(z)+\psi^{\prime}(z)\right] \\
2 M\left(u_{x}+\mathrm{i} u_{y}\right)=\kappa \varphi(z)-z \overline{\varphi^{\prime}(z)}-\overline{\psi(z)}
\end{array}\right.
$$

with:

$$
\begin{aligned}
& M=E / 2(1+\nu v)=\text { shear modulus of the solid; } \\
& \kappa \kappa=3-4 \nu \nu(\text { case of plane deformation); } \\
& \nu \nu=\text { Poisson's ratio; } \\
& \mathrm{E}=\text { Young's modulus. }
\end{aligned}
$$

$\sigma \mathrm{s}_{\mathrm{xx}}, \sigma \mathrm{s}_{\mathrm{yy}}$ and $\sigma \mathrm{s}_{\mathrm{xy}}$ are the normal and tangential constraints, $\mathrm{U}_{\mathrm{x}}$ and $\mathrm{U}_{\mathrm{y}}$ are the horizontal and vertical displacements. By referring the relation (1) in equations (2) we obtain:

$$
\left\{\begin{array}{l}
\sigma_{x x}+\sigma_{y y}=4 \Re \mathrm{e}\left[\frac{\varphi^{\prime}(\zeta)}{\omega^{\prime}(\zeta)}\right] \\
\sigma_{y y}-\sigma_{x x}+2 \mathrm{i} \sigma_{x y}=\frac{2}{\omega^{\prime}(\zeta)}\left[\overline{\omega(\zeta)} \frac{\mathrm{d}}{\left.\mathrm{d} \zeta\left(\frac{\varphi^{\prime}(\zeta)}{\omega^{\prime}(\zeta)}\right)+\psi^{\prime}(\zeta)\right]}\right. \\
2 M\left(u_{x}+\mathrm{i} u_{y}\right)=\kappa \varphi(\zeta)-\frac{\omega(\zeta)}{\overline{\omega^{\prime}(\zeta)}} \frac{\bar{\psi}(\zeta)}{\varphi^{\prime}(\zeta)}
\end{array}\right.
$$

It is also possible to calculate the stresses and displacements in polar coordinates $(\rho, \theta)$ in the plane $(\mathrm{O}, \mathrm{x}, \mathrm{y})$. Fig. 4 shows components of the stress tensor in Cartesian and polar coordinates. 


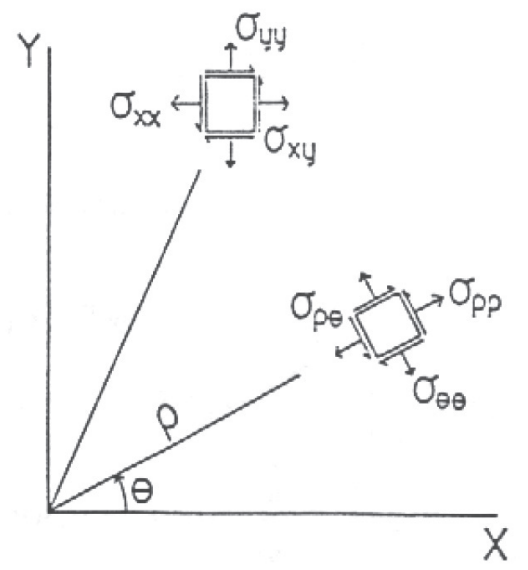

Fig. 4. Representation of the components of the stress stretcher in Cartesian and Polar coordinates

4. ábra Feszültségkomponensek reprezentációja derékszögü és poláris koordinátarendszerekben

For the computation of the stresses and displacements in polar coordinates one uses the laws of transformations following (Muskhelishvili, 1977):

$$
\left\{\begin{array}{l}
\sigma_{\rho \rho}+\sigma_{\theta \theta}=\sigma_{x x}+\sigma_{y y} \\
\sigma_{\theta \theta}-\sigma_{p \rho}+2 \mathrm{i} \sigma_{\rho \theta}=\mathrm{e}^{2 \mathrm{i} a}\left(\sigma_{y y}-\sigma_{x x}+2 \mathrm{i} \sigma_{x y}\right) \\
u_{\rho}+\mathrm{i} u_{\theta}=\mathrm{e}^{-\mathrm{i} \alpha}\left(u_{x}+\mathrm{i} u_{y}\right)
\end{array}\right.
$$

$\alpha$ is defined as follows. Let $\mathrm{P}(\zeta)$ be a point on the plane plan $(\mathrm{O}, \zeta 1, \zeta 2)$ and $\omega P)(z$, its image in the plane $(\mathrm{O}, \mathrm{x}, \mathrm{y})$. By the transformation $\omega \omega$, the line $\Delta(\theta=$ constant $)$ is transformed into the hyperbola branch $\omega(\Delta)$. $\alpha$ is the angle the tangent makes to $\omega(\Delta)$ in $\omega(\mathrm{P})$ white $(\mathrm{Ox})$.

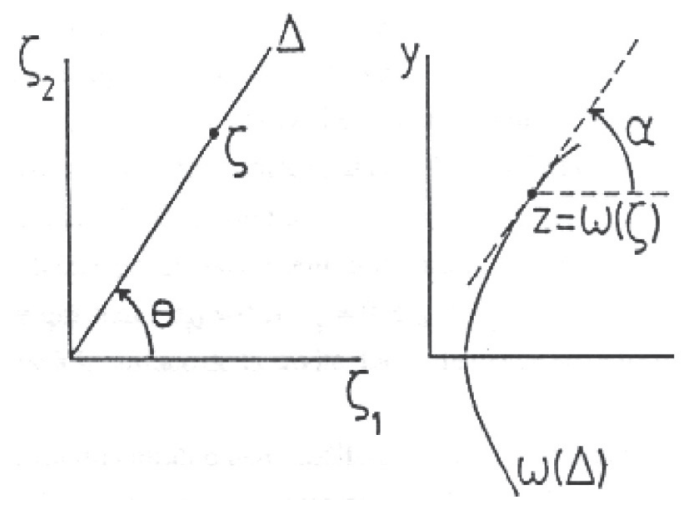

Fig. 5. Transformation of line $\Delta(\theta=$ constant $)$ into hyperbolic branch $\omega(\Delta)$

5. ábra Vonaltranszformáció $\Delta(\theta=$ konstans $)$ hiperbolává $\omega(\Delta)$

In other words, $\alpha$ is the angle, in $\mathrm{z}=\omega(\zeta)$, between the normal to the ellipse image of the circle ( $\rho=$ constant $)$ and $(\mathrm{Ox})$. We show that:

$$
e^{i \alpha}=\frac{\varsigma^{2}}{\rho^{2}} \frac{\omega^{\prime}(\varsigma)}{\omega^{\prime}(\varsigma)}
$$

By referring (4) to (3), we obtain:

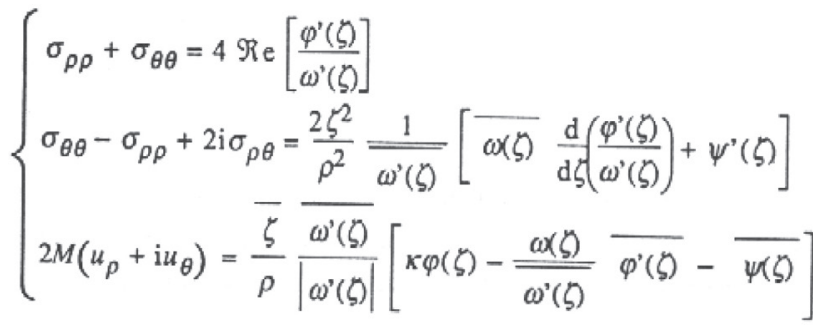

Relationships (5) are useful when one is interested in the state of stresses at the surface of the elliptic hole $(\rho \rho=1)$ since $\sigma_{\rho \rho}, \sigma_{\theta \theta}$ and $\sigma_{\rho \theta}$ are the normal and tangential stresses at the surface. We will therefore calculate the potentials $\varphi \varphi$ and $\psi \psi$ according to the variable $\zeta \zeta$ and then using the transformation $\mathrm{z}=\omega \omega(\zeta \zeta$ ), we will be able to calculate the stresses and displacements in the plane $(\mathrm{O}, \mathrm{x}, \mathrm{y})$.

\section{Computer programming}

To study the problem of Haoud Berkaoui, we followed the procedure:

- Before the dissolution of the sodium chloride by the water of the Albian, there is continuity of the stresses through the surface of the potential cavity. The stress along this surface is vertical and equal to the weight of the overlying land.

- Subsequently the salt is dissolved in the cavity but fictitiously maintained inside the cavity a stress field which counterbalances the weight of the ground in every point of the surface: the system remains in its original state.

- This constraint is gradually released to reach the new equilibrium conditions which are: $\sigma_{\mathrm{N}}=0$ and $\sigma_{\mathrm{T}}=$ 0 (free surface) where $\sigma_{\mathrm{N}}$ and $\sigma_{\mathrm{T}}$ are the normal and tangential stresses to the cavity surface. During this relaxation, the cavity is deformed elastically.

Relaxation causes a modification of the displacement and stress fields inside the surrounding environment, especially on the surface of the Earth. To calculate these different fields, we consider that the new equilibrium situation corresponds to the conditions that prevail in the medium for a cavity charged by $\sigma_{0 \mathrm{~N}}$ and $\sigma_{0 \mathrm{~T}}$, the normal and tangential stresses applied to the surface of the cavity before relaxation, that is to say related to the weight of the grounds.

The weight of the grounds or lithostatic stress is given by:

$$
\sigma_{\mathrm{v}}=d g h
$$

with:

$$
\begin{aligned}
& \mathrm{d}=\text { density of the land; } \\
& \mathrm{g}=\text { acceleration of gravity; } \\
& \mathrm{h}=\text { depth }
\end{aligned}
$$

This stress varies along the surface of the cavity as a function of the depth of the point of application. This point $z=\mathrm{x}+$ iy is the image of a point $\zeta=\rho \mathrm{e}^{\mathrm{i} \theta}$ by the transformation $\omega$. The depth $h$ of this point and its y-coordinate in a coordinate system linked to the center of the cavity are linked by $h=H-y$. Now, $\mathrm{y}=\mathrm{b} \sin \left({ }^{*}\right)$. And the constraint $\mathrm{V}$ is thus given by: $\mathrm{V}$ is thus given by: $\sigma$ by the transformation $\left({ }^{*}\right)$. The depth $h$ of this point 
and its y-coordinate in a coordinate system linked to the center of the cavity are linked by $\mathrm{h}=\mathrm{H}-\mathrm{y}$. Now, $\mathrm{y}=\mathrm{b} \sin \theta$. And the constraint $\sigma_{\mathrm{v}}$ is thus given by:

$$
\sigma_{\mathrm{v}}=d g(H-b \sin \theta)
$$

Using relations (4), it is then possible to calculate at any point on the surface of the cavity the normal stress $\sigma_{0 \mathrm{~V}}\left(=\sigma_{\rho \rho}, \sigma_{\theta \theta}\right)$, and the tangential stress $\sigma_{0 \mathrm{~V}}=\left(\sigma_{\rho \theta}\right)$ associated.

The computer program will consist of the following sequence:

- Regular distribution of measurement stations of stress fields and displacements on the surface of the Earth;

- Cutting the contour of the cavity into a number of segments (generally 100). On each segment are calculated $\sigma_{0 \mathrm{~T}}$ and $\sigma_{0 \mathrm{~N}}$ depending on the depth of the mid-segment point;

- Calculating at each station the surface of the stresses and displacements due to $\sigma_{0 \mathrm{~T}}$ and $\sigma_{0 \mathrm{~N}}$ by using the complex potentials corresponding to this type of loading of an elliptical cavity segment;

- Summation of the effects of all the segments of the cavity of each station of the surface;

- Drawing of the stress curves and surface displacements by a suitable software.

Two cases can be distinguished according to whether or not the length of the minor axis of the cavity is neglected in front of its depth. In the first case, we can consider that we are in first approximation in the case of the cavity uniformly loaded by a normal stress $\sigma_{0 \mathrm{~N}}=d g(H-b)$.

It is then not necessary to segment the contour of the cavity and one can use the simplified complex potentials corresponding to this loading geometry. In the second case, the procedure described above applies.

\section{Trace and interpretation of curves}

The parameters of the model that we retain are the following:

- half-major axis of the cavity a = $200 \mathrm{~m}$;

- half-small axis b = $100 \mathrm{~m}$;

- depth of the center of the cavity $\mathrm{H}=448 \mathrm{~m}$;

- average Young's modulus for the overlying layers $\mathrm{E}=$ 8-10-10 Pa;

- average Poisson's ratio $\mathrm{v}=0.28$;

- average density $\mathrm{d}=2650 \mathrm{~kg} / \mathrm{m}^{3}$.

Except for a, the parameters were selected based on existing data and assuming that the entire thickness of the salt layer was dissolved. The value of $a$ was chosen arbitrarily since no constraint allows to constrain it. The number of stations on the surface is $n_{s}=100$ and the number of segments on the perimeter of the cavity is $n_{e}=100$. Two series of curves have been drawn:

a) Case where the cavity is uniformly loaded: curves 1.1, 1.2, 1.3, 1.4 and 1.5.

b) Case where the cavity is not uniformly loaded: 2.1, 2.2, 2.3, 2.4 and 2.5.

For each case we have plotted the following curves:

Normal and tangential stresses at the surface:
1) $\sigma_{\mathrm{xx}},=f((x / a)$
2) $\sigma_{\mathrm{yy}}=f((x / a)$
3) $\sigma_{\mathrm{xy}}=f((x / a)$.

Vertical and horizontal surface displacements:

1) $u_{y}=f((x / a)$.

2) $u_{x}=f((x / a)$.

Table 1 shows the variations of the stress and displacement values plumb with the cavity $(\mathrm{x}=0)$ for different values of a and $b$.

\begin{tabular}{cccccccc}
\multicolumn{2}{c}{ Dimensions } & \multicolumn{3}{c}{$\begin{array}{c}\text { Constraints } \\
\left(\mathbf{1 0 ^ { 5 }} \mathbf{~ P a}\right)\end{array}$} & \multicolumn{2}{c}{$\begin{array}{c}\text { Displacement } \\
\left(\mathbf{1 0 ^ { - 3 }} \mathbf{~ m}\right)\end{array}$} \\
$a(\mathbf{m})$ & $b(\mathbf{m})$ & H/a & $\sigma_{x x}$ & $\sigma_{y y}$ & $\sigma_{x y}$ & $u_{x}$ & $U_{y}$ \\
100 & 50 & 4.48 & 23 & 1.32 & 34.40 & 5.40 & 3.19 \\
200 & 100 & 2.24 & 47 & 1.54 & 79.40 & 7.90 & 4.11 \\
300 & 150 & 1.49 & 72 & 1.87 & 122.10 & 8.69 & 5.79 \\
400 & 200 & 1.12 & 97 & 9.90 & 156.00 & 20.80 & 17.40
\end{tabular}

Table 1 Variations of the calculated stress and displacement 1. táblázat Számított feszültségek és alakváltozások

\section{Interpretation}

The most interesting information that can be drawn from the curves and Table 1 are:

a) In the case of Haoud Berkaoui (horizontal underground cavern approximated by an ellipse), we observe a maximum displacement perpendicular to the cavity and a symmetrical plot on both sides of this point, for the uniform loading. In non-uniform loading, the maximum is displaced laterally but the curve remains symmetrical. For the horizontal displacement, the curve passes by 0 in line with the hole and is antisymmetric with respect to this point. This observation is quite logical given the symmetry of loading.

b) Curves tend to zero to infinity: the effect of the cavity decreases with distance.

c) The normal stress $\sigma_{\mathrm{yy}}$ passes through a maximum above the hole for both types of loading and is symmetrical with respect to this point. It is the same for the horizontal stress $\sigma_{x x}$ whereas the tangential stress $\sigma_{x y}$ is antisymmetric and goes through zero at this point.

d) Surface displacements decrease when the depth / halflength ratio increases.

\section{Determination of a rupture criterion}

It is possible to determine graphically from which value of stress it is possible to have potential breaks in the surface. The three basic modes of rupture are represented by Fig. 6 .

In the case of an extension rupture (vertical cracking), a criterion of the type $\sigma_{x x} \geq \sigma_{0}$, where $\sigma_{0}$ is the tensile strength of the rock. In the case of shear failure, a Mohr-Coulomb failure criterion is used:

$$
\left|\sigma_{\mathrm{T}}\right| \geq \mathrm{S}_{0}+\mu\left|\sigma_{\mathrm{N}}\right|
$$

with: $\sigma_{\mathrm{T}}=$ tangential stress applied along a potential plane of rupture;

$\sigma \mathrm{s}_{\mathrm{N}}=$ normal stress applied on the same plane;

$\mathrm{S}_{0}=$ shear strength of the rock;

$\mu=$ coefficient of friction of the rock. 


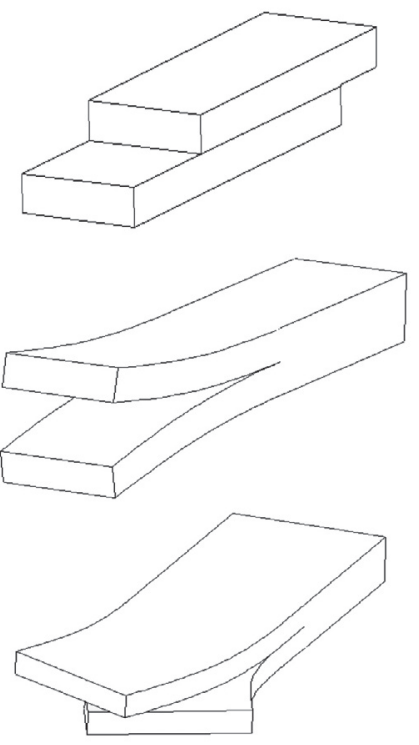

Mode I or Traction:

Perpendicular opening of the lips of the crack under the action constraints of extension.

\section{Mode II or Shear:}

Slip of the crack lips in a direction perpendicular to the front of the crack.

\section{Mode III or Twist:}

Relative sliding of the lips of the crack in a direction parallel to the front of the crack.

Fig. 6. Representation of the fundamental modes of rupture 6. ábra Jellegzetes törési módok bemutatása

In this case, look for the potential break plane (inclined to the horizontal). Thus, knowing $\sigma_{\mathrm{xx}}, \sigma_{\mathrm{xy}}$ and $\sigma_{\mathrm{yy}}$ on the surface, we can calculate for a plane of inclination the values of $\sigma_{\mathrm{N}}$ and $\sigma_{\mathrm{T}}$ namely :

$$
\begin{aligned}
& \sigma_{N}=\frac{\sigma_{x x}+\sigma_{y y}}{2}-\frac{\sigma_{x x}-\sigma_{y y}}{2} \cos 2 \beta-\sigma_{x y} \sin 2 \beta \\
& \sigma_{T}=-\frac{\sigma_{x x}-\sigma_{y y}}{2} \sin 2 \beta+\sigma_{x y} \cos 2 \beta
\end{aligned}
$$

The plane of rupture is that by which the preceding criterion is respected. To go beyond this qualitative analysis, real, accurate and up-to-date data is absolutely necessary.

\section{Conclusions}

The setting up of a theoretical framework necessary for the understanding of the complex problem of the oil well of Haoud Berkaoui is essential for its possible control. Modeling the case of Haoud Berkaoui, a rare and perhaps unique case in the world, will make it possible to better understand this phenomenon and to theoretically predict the areas of potential disruption in the region and to act effectively in the context of behavior monitoring and the evolution of this delicate problem, especially as its direct resolution is made impossible because of the existence of large and deep cracks around the big hole that put the life of potential stakeholders in danger of death.

The work done at the Laboratory of Physics of Materials at the School and Observatory of Physics of the Globe of Strasbourg (IPGS) consisted essentially of the modeling of the elastic deformation in an infinite plate, pierced with a hole this in order to examine the mechanical relation between the loading of the hole and the process of rupture.

Computer programming has consisted of studying the case where the cavity is loaded uniformly or non-uniformly. During the dissolution of the sodium chloride in the cavity, the latter deforms elastically, resulting in a change in displacement fields and constraints including the surface of the Earth.
This programming is based on the regular distribution of measurement stations of the stress fields and displacements on the surface of the Earth, the cutting of the contour of the cavity into segments and for each segment the calculation of the normal and tangential stresses in each station. The surface. Then we sum the effects of all the segments of the cavity and we trace the curves of stresses and displacements on the surface.

The effects of all the segments of the cavity are then summed and the stress and displacement curves are plotted on the surface. For more accurate results (real, accurate and upto-date problem data is needed), it is necessary to use the iteration method (successive overlays), a method based on the readjustments of constraints while respecting the initial boundary conditions. This method takes into account the interaction between the free surface and the underground hole. We proceed by successive overlays until the corrective fields on the free surface and the hole are negligible.

As a preventive measure, studies have been carried out (Mellak. A., Baudeau, P., 1994), (Mellak, A., Bekkour, K., 1997); (Mellak, A., 2000) to avoid the technical faults that led to the formation of a gigantic underground cave and a major surface collapse, in other words, the formation of other Haoud Berkaoui in Algeria or elsewhere.

\section{References}

[1] Jaeger, J. C. - Cook, N. G. W. (1979): Fundamentals of rock mechanics, $3^{\text {rd }}$ ed., Chapman and Hall, London.

[2] Stephenson, A. (1982): Landolt - Börnstein - Numeral data and functional relationships in science and technology, Volume 1: Physical properties of rocks, G. Angenheister Ed., Springer-Verlag, Berlin.

[3] Mellak, A. - Reuschlé, T. - Gueguen, Y. (1990): Mécanique de la rupture, modélisation de Haoud Berkaoui. Rapport du D.E.A. Mécanique et Acoustique - Ecole et Observatoire de Physique du Globe de Strasbourg.

[4] Mellak, A. - Baudeau, P. (1994): Propriétés physico-chimiques des coulis de ciment saumurés et microsilicés appropriés aux formations salifères in Annales de l'Institut Technique du Bâtiment et des Travaux Publics - Paris, $\mathrm{n}^{\circ} 526$, pp. 70-86.

[5] Mellak, A. - Bekkour, K. (1997): Comportement rhéologique des coulis de ciment saumurés in 13ème Congrès Français de Mécanique, Poitiers Futuroscope, pp. 397-400.

[6] Mellak, A. (2000): Environmental geology: major collapse risk in an oilbearing region, in Fifth International Conference on the Geology of the Arab World GAW-5, February 21-24, 2000 of Faculty of science, Cairo University - Egypt.

[7] Muskhelishvili, N. I. (1977): Some basic of the mathematical theory of elasticity, $4^{\text {th }}$ Ed., Noordhoff International Publishing, Leyden, The Netherlands.

[8] Pollard, D. D. - Holzhauzen, G. (1979): Mechanical interaction between a fluid-filled fracture and the Earth's surface, Tectonophysics, Vol. 53, pp 27-57. https://doi.org/10.1016/0040-1951(79)90353-6

[9] Reuschlé, T. (1979) Les fluides et lévolution des propriétés mécaniques des roches. Doctorat de l'université Louis Pasteur de Strasbourg.

[10] Mellak, A. (2017): From Nuclear to Cogeneration - How a natural disaster can change the policy of a country, Éitöanyag - Journal of Silicate Based and Composite Materials, Vol.69, No.4, pp. 114-115. https://doi.org/10.14382/epitoanyag-jsbcm.2017.20

$\underline{\text { Ref.: }}$

Mellak, Abderrahmane: Mathematical modelling: case of Haoud Berkaoui Építőanyag - Journal of Silicate Based and Composite Materials, Vol. 71, No. 1 (2019), 12-16. p.

https://doi.org/10.14382/epitoanyag-jsbcm.2019.3 